\title{
1 WEIRD People and The Western Church: who made who?
}

Preprint. Paper in press at Religion, Brain \& Behavior.

4

5 Authors: Passmore, $\mathrm{S}^{1} \&$ Watts, $\mathrm{J}^{2,3,4}$

$6{ }^{1}$ Faculty of Environment and Information Studies, Keio University SFC (Shonan Fujisawa

7 Campus)

$8 \quad{ }^{2}$ Religion Programme, School of Social Sciences, University of Otago, Dunedin, New

9 Zealand

${ }^{3}$ Center for Research on Evolution, Belief and Behaviour, University of Otago, Dunedin, 11 New Zealand

${ }^{4}$ Department for Linguistic and Cultural Evolution, Max Planck Institute for the Science of Human History, Jena, Germany

Henrich's The WEIRDest People in the World explains how the West came to be psychologically and culturally WEIRD (Western, Educated, Industrialized, Rich, Democratic), and the economic and social effects this has had on the last two thousand years of human history. One of the many strengths of WEIRDest People in the World is that it synthesizes evidence from psychology, economics, anthropology, and history into an integrated, compelling, and coherent theoretical framework. In this book, kinship is positioned at the forefront of narratives about the evolution of human societies - something that has long been recognized within anthropology but often missing from grand history narratives (Diamond, 1999; Harari, 2014). This work is highly readable while still making clear, empirically testable causal hypotheses. A central hypothesis of Henrich (2020) is that the Western Christian Church's Marriage and Family Program (MFP) caused changes in European kinship systems. Here we evaluate the evidence presented in support of this hypothesis by reviewing the available information on pre-MFP kinship systems in Europe and re-analyzing cross-national associations between MFP and kinship structures using phylogenetic comparative methods. We raise alternative hypotheses about the relationships between the Western Christian Church and kinship structures and suggest that further research is needed to arbitrate these hypotheses. 


\section{Does MFP cause changes in kinship intensity?}

According to Henrich, the MFP began in the $4^{\text {th }}$ century, when the Western Christian Church (henceforth, the Church) institutionalized a host of policies that functioned to break down the kin-based institutions of European society. These policies came in the form of a continuous history of decrees, condemnations, letters, and laws beginning in 305CE, which increased in frequency in the $7^{\text {th }}$ and $8^{\text {th }}$ centuries (documented in Appendix A of Henrich (2020)). The Church's policies involved the recombination and adjustment of beliefs and practices from existing religious and social systems - specifically involving social norms for kinship. The Church's institutionalized breakdown of kin-based society consequently changed the psychology of individuals and the social structure of society from a kin-oriented system to a system that allowed and necessitated individualized psychology and the cooperation of unrelated individuals. The importance of kin-based institutions within a society are summarized as kinship intensity. The concept of kinship intensity used in Henrich (2020) relates to the existing literature on intensive and extensive kinship systems (Bugos, 1985; Bailey, Hill, \& Walker, 2014; Shenk, Towner, Voss, \& Alam, 2016), as well as how kin-dense social networks are within a society (Colleran, 2020). The kinship intensity index (KII) quantifies the relative strength of kin-based institutions in a society, as defined within Schulz, Bahrami-Rad, Beauchamp, and Henrich (2019), and is used throughout Part 2 of Henrich (2020). A shift to an impersonal psychology allowed a prosocial model of voluntary cooperation to develop and in turn granted the opportunity for impersonal markets (demarcated from markets driven by personal relationships) to flourish. The rise of impersonal markets ultimately lead to the commercial and urban revolutions that built and shaped modern European society.

According to Henrich (2020), the change in kinship intensity within Europe was caused by the Church's MFP. Contemporary evidence suggests that the breakdown of kinbased institutions often stems from an increase in market integration (Shenk et al., 2016; Colleran, 2020). With increased market integration comes an increased need for mobility (moving for work), and the ability to provide resources for yourself and immediate family (through wage labor and markets). The ability for people to provide for themselves means a reliance on kin is no longer necessary, and is sometimes a hindrance, resulting in a breakdown of kinship ties. Henrich (2020) states that the breakdown of kinship systems in European history was different from elsewhere, with the breakdown in European kin-based institutions occurring before the rise of impersonal markets, and importantly MFP was the reason for their breakdown. 
There are two main sources of evidence used to support the claim that the Church's MFP caused changes in kin-based institutions. The first are historical examples of institutional policies, letters, and edicts from Christian leaders and throughout Europe between the $4^{\text {th }}$ and $20^{\text {th }}$ century, indicative of top-down change in kin-based institutions. The second is the cross-national relationship between kinship intensity and psychological diversity found in a recent article by Henrich and colleagues (Schulz et al., 2019).

\section{Evaluating Evidence from Historical Case Studies}

The WEIRDest People in the World draws on an extensive number of letters, policies and edicts concerning family structures. Examples include the $305 \mathrm{CE}$ decree from the Synod of Elvira banning the marriage of a widower to his wife's sister (sororate marriage), Pope Gregory I's 600CE letter prohibiting first cousin marriage, and the $874 \mathrm{CE}$ ban on thirdcousin marriage in Douci, which made children of an incestuous marriage ineligible for succession. Within Henrich (2020), these examples are interpreted as evidence that top-down changes in law and church policy shifted the kinship and marriage practices of Europe at the time.

An assumption made in Henrich (2020) is that Church policies, letters, and edicts represent the beginnings of changing kinship structure in Europe, and that this change occurred through the Church imposing top-down rules on populations. An alternative hypothesis is that Church policies are symptomatic of broader social changes occurring within populations (alternative model 1, Figure 1). For example, the attitudes of Church leaders may simply have reflected the changing times, and the availability of written records may reflect who was literate within early European societies. Another alternative hypothesis is that Church's MFP and kinship practices co-evolved with one another (alternative model 2, Figure 1). For example, the Church's policies could have reinforced and formalized processes of change in kinship that had already been set in motion. These alternative hypotheses differ from the causal claims set out in Henrich (2020) in that they suggest the Church's position on kinship structures were, at least in part, influenced by broader patterns of change occurring within Europe at the time. By suggesting the Church was influenced by broader social change, these models allow for the possibility of kinship changes to arise and spread throughout populations, rather than being imposed top-down by leaders. These alternative hypotheses also reflect different perspectives on the relationship between religion and society, as well as the ways in which cultural systems change (Smaldino, 2014). 
Model proposed
in Henrich

Alternative model 1

Alternative model 2

Alternative model 3
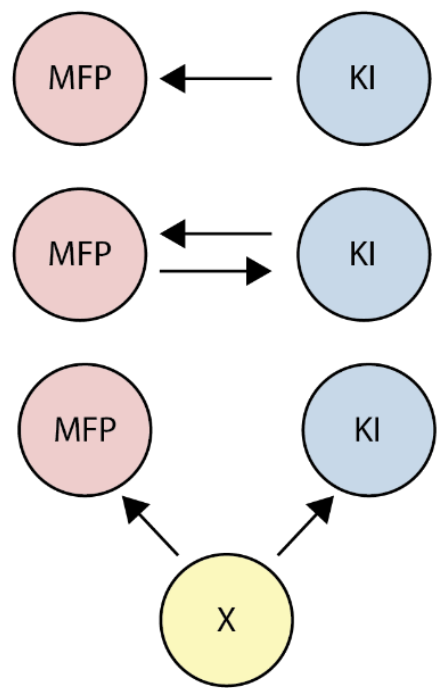

Alternative model 4

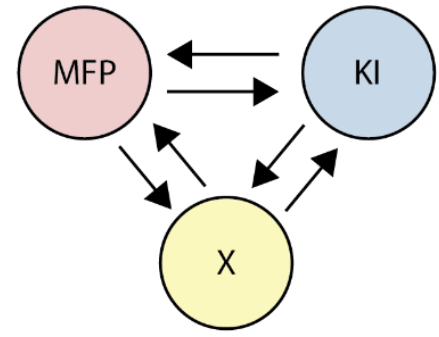

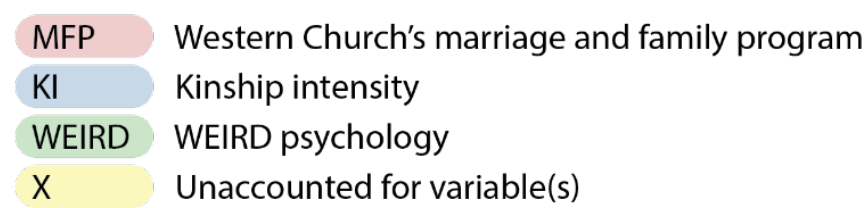

100 Figure 1. Causal relationships between MFP and kinship intensity (KI). The first model

101 shows the causal relationship proposed in Henrich (2020), according to which the Church's

102 MFP caused changes in kinship intensity. Alternative model 1 shows the kinship intensity of

103 societies influencing the Church's MFP. Alternative model 2 shows an interaction between

104 MFP and kinship intensity. Alternative model 3 shows a third variable (or variables)

105 producing changes in kinship intensity. Alternative model 4 shows all three variables

106 interacting with one another.

To evaluate the hypotheses in Figure 1, it would ideally be possible to examine the kinship structures of European societies before and after implementation of the Church's

110 MFP. Unfortunately, there is a paucity of information on the kinship and marriage practices

111 of many European populations in the early stages of the Church. Within the Roman empire, 
written historical records are limited to the lives of the rich and powerful, and usually only the men of this subset - representing a tiny proportion of the population (Knapp, 2011). The information left by this population was often done intentionally and tells us little about the behaviors of the general population. However, there is sometimes scope to analyze incidental evidence. For example, the available written historical records suggests that at least parallelcousin marriage (marrying children of your parent's same-sex sibling) was rare prior to 300CE in Roman aristocracy (Shaw \& Saller, 1984). We note that the ethnographic record indicates that parallel cousin marriage is uncommon outside Arabic societies (Murphy and Kasdan, 1959), and has a low global frequency (4.5\% of the Ethnographic Atlas; Kirby et al. 2016), meaning that the scarcity of parallel cousin marriage in early Europe is not particularly informative. Information on other forms of cousin marriage during the early stages of the Church's MFP in Europe is scarce - indicated by Henrich's (2020) use of $20^{\text {th }}$ century cousin marriage rates (pg. 238). Inferences from cultural phylogenetic reconstructions and genetic histories indicate that monogamy is likely to have been common from at least the Neolithic (Fortunato, 2011; Rasteiro \& Chikhi, 2013; Scheidel, 2009). The reconstructed evidence of monogamy suggests that some changes in kinship intensity associated with the Church's MFP had already occurred earlier in European history. These reconstructions of monogamy provide information on only one aspect of kinship and marriage systems. In general, there is insufficient evidence to build a rich picture of pre-MFP kinship practices in European society, but the scarce evidence available suggests that at least some of the core features of MFP may already have been present within European society before the Church implemented its MFP. While we may never have a clear picture of the relationship between the Church and kinship in early Europe, it is possible to examine the interaction between kinship structure and the Church in more recent times and across other nations to infer relationship in the past - which is a second line of evidence drawn upon in Henrich (2020).

\section{Evaluating Evidence from a Cross-National Study}

A cross-national study of kinship intensity and exposure to the Church provides a second core line of evidence that the Church drove changes in kinship intensity (Schulz et al., 2019). Across a sample of 146 nations, this study found that the greater the number of years of exposure to the Church, the lower the country's level of kinship intensity today. We raise two issues with this analysis: how the variable "Western Church exposure" is defined, and a need to control for cultural interdependencies. We only focus on the global, cross-national analyses from Schulz et al (2019) but the concerns raised here potentially also apply to all 
parts of the study where the Western Church exposure variable is used and cross-national analyses are performed.

The variable "Western Church Exposure" used by Schulz et al. (2019) is defined as the number of years that a nation has had both a Christian leader, and importantly, that the leader had implemented the Church's MFP policies (Schulz, 2018). By conditioning the Church exposure measurement to nations where MFP laws were implemented, this variable overlooks those nations where the Church was present but institutionalized change in kinship practices did not occur. The structure of conditioning means that both these variables are measures of kinship within a society: one is, in part, a measure of kinship laws ("Western Church Exposure"), and the other is a measure of kinship practices ("kinship intensity index"). An alternative explanation for the relationship between kinship intensity and presence of MFP is that nations with looser kinship systems are more likely to have leaders that are willing to implement the Church's MFP. An explanation where MFP nations are more likely to have leaders who implement the program aligns with alternative model 1 and alternative model 2 (Figure 1), suggesting that the level of kinship intensity influences the Church's policies, rather than just involving the Church imposing a top-down process of cultural change.

The second issue concerns the interdependence of data points when modelling crosscultural (or cross-national) data. In Schulz et al. (2019), it is shown that each additional 100 years under the Church are affiliated with a 0.24 standard deviation change in the kinship intensity index. However, two nations that are close to each other (either through time by sharing recent common ancestor or by being geographically adjacent), are more likely to be similar than two nations that are less close to one another, also known as autocorrelation (Bromham et al. 2018; Roberts \& Winters, 2013). Within macro-cultural evolution studies, historical relationships are commonly controlled for using linguistic phylogenies (Evans, Greenhill, Watts, List, Botero, Gray, \& Kirby, 2021), which have been shown to be particularly important in the analysis of kinship systems (Guglielmino, Viganotti, Hewlett, \& Cavalli-Sforza, 1995; Jordan \& Dunn, 2010; Passmore \& Jordan, 2020).

We reanalyzed the relationship between exposure to the Church and kinship using Bayesian phylogenetic repeated measures mixed model (Bürkner, 2018). In these analyses we used a language tree as a proxy for the historical relationships between the global sample of societies (Jäger, 2018). This tree was generated through the automated similarity judgment program of 40 concepts across 7,000 languages. The automatically generated language tree only coarsely represents the relationships between societies but is sufficient for providing a 
180 first-pass assessment of the effect of autocorrelation in this dataset. Nations were assigned 181 languages based on the most widely spoken language within each country. After making connections between nations, languages, and phylogeny, we have a subset of 148 nations, 183 from a complete dataset of 160 nations.

Since we are implementing the models in a Bayesian framework, we first replicate the relationship between Church exposure and kinship intensity from Schulz et al. (2019), then secondly, include phylogenetic covariances into the model. Using our approach, we can replicate the results from the model predicting KII with exposure to the Western and Eastern Church (table S4.8, Panel 1, column 1 in Schulz et al., 2019): an additional 100 years of Western Church exposure reduces the KII by 0.23 standard deviations ( $95 \%$ CI: -0.27 , 0.18). Additionally, we find exposure to the Eastern Church reduced KII by 0.19 standard deviations, a result negligibly different from the original (95\% CI: $-0.30,-0.08)$. However, when controlling for phylogenetic relationships, an additional 100 years of exposure to the Western Church only reduces KII by 0.06 standard deviations - less than half the original effect (95\% CI: $-0.10,-0.01$; Figure 2). Additionally, within the phylogenetically controlled model, we estimate the size of phylogenetic signal in the residuals to be 0.91 , highlighting the importance of controlling for autocorrelational processes when modelling cross-cultural data. Supplementary information on the models run here are available at https://osf.io/rzk34/.

198 Further models with alternative measures of cultural ancestry and additional control variables 199 are warranted. 


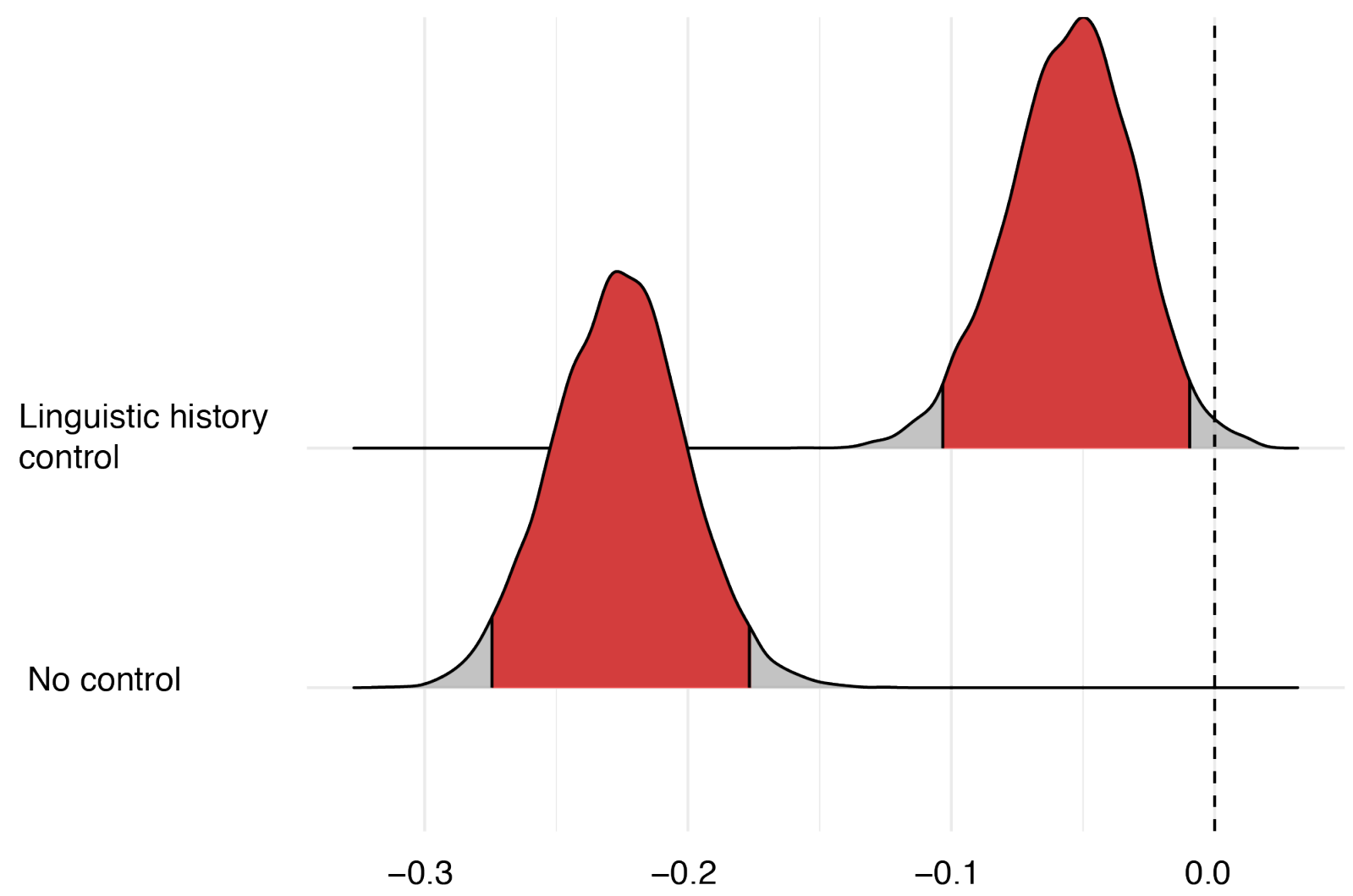

207 Figure 2. Posterior distribution of beta coefficient for Western Church exposure across

208 models with and without a linguistic history control. Red sections represent $95 \%$ confidence 209 intervals.

The results of the phylogenetically controlled analysis are consistent with the

212 hypothesis that exposure to the Western Church is negatively related to kinship intensity, 213 presented in Henrich (2020). However, the magnitude of the relationship between Church 214 exposure and kinship intensity is considerably reduced, which decreases confidence in the 215 practical significance of this relationship. The result of our phylogenetic model suggests that 216 the spread of MFP legislation and changes in kinship practices within populations are both 217 highly related to the linguistic communities that they are part of.

218 This suggests that language, kinship systems, and religion are part of a core package 219 of cultural traits that are stably inherited over long periods of time, as is illustrated in 220 alternative model 3 and alternative model 4 of Figure 1. Both alternative model 3 and 221 alternative model 4 differ from the hypothesis presented in The WEIRDest People in the 222 World by emphasizing the importance of an external variable that influences both kinship intensity and MFP. Alternative model 3 represents a simple causal fork in which both kinship intensity and the Church's MFP are products of a third factor (Pearl \& Mackenzie, 2018).

225 Alternative model 4 hypothesizes that the relationship proposed in Henrich (2020) exists 
within a complex web of religion, kinship, language, and other cultural components that are absent from the theoretical model proposed in Henrich (2020). While complex, we believe that alternative model 4 is likely to be closer to the true historical relationship between these variables than the unidirectional model proposed in Henrich (2020). Systematic cross-cultural research is needed to identify the relative importance of the causal relationship defined in these models.

\section{Conclusion}

The WEIRDest People in the World sets out hypotheses that will inspire future research, highlights the importance of cultural evolutionary frameworks, and sets a new standard for inter-disciplinary theoretical syntheses. In this review, we have highlighted that the evidence presented for the causal relationship between the Church's MFP and changes in kinship intensity is also compatible with alternative causal models (Figure 1). These alternative models differ from Henrich (2020) in the nature of the relationship between religion and society, processes of cultural change, and the factors shaping kinship systems.

We have presented a number of reasons to think that the relationship between the Church's MFP and kinship practices is more complicated than the unidirectional hypothesis outlined in Henrich (2020). Despite little available information on the kinship systems of societies within Europe before the Church's MFP, at least some core features of the Church's MFP are likely to have been common in Rome prior to the Western Church (Fortunato, 2011; Rasteiro \& Chikhi, 2013; Scheidel, 2009). This suggests that MFP was informed by, and potentially reinforced, changing kinship systems, rather than acting as the primary driver of kinship change. Additionally, our reanalysis of the cross-national data by Schulz et al. (2019) suggests that the relationship between church exposure and kinship intensity can be largely (but not entirely) explained by the common cultural ancestry of nations. Further research is needed to systematically test the causal claims set out by Henrich (2020) and evaluate alternative causal hypotheses.

\section{Acknowledgements}

We would like to thank Dr Caitlin Greenwood for her advice on Roman history and literature, as well as Associate Professor John Shaver for feedback and comments. 
Bailey, D. H., Hill, K. R., \& Walker, R. S. (2014). Fitness consequences of spousal relatedness in 46 small-scale societies. Biology Letters, 10(5), 20140160. https://doi.org/10.1098/rsbl.2014.0160

Bromham, L., Hua, X., Cardillo, M., Schneemann, H., \& Greenhill, S. J. (2018). Parasites and politics: Why cross-cultural studies must control for relatedness, proximity and covariation. Royal Society Open Science, 5(8), 181100. https://doi.org/10.1098/rsos.181100

Bugos, P. E. (1985). An evolutionary ecological analysis of the social organization of the Ayoreo of the Northern Gran Chaco. Northwestern University.

Bürkner, P.-C. (2018). Advanced Bayesian Multilevel Modeling with the R Package brms. The R Journal, 10(1), 395-411. https://doi.org/doi: 10.32614

Colleran, H. (2020). Market integration reduces kin density in women's ego-networks in rural Poland. Nature Communications, 11(1), 266. https://doi.org/10.1038/s41467-01914158-2

Diamond, J. M. (1999). Guns, germs, and steel. W. W. Norton.

Evans, C. L., Greenhill, S. J., Watts, J., List, J. M., Botero, C. A., Gray, R. D., \& Kirby, K. R. (2021). The uses and abuses of tree thinking in cultural evolution. Philosophical Transactions of the Royal Society B, 376(1828), 20200056

Fortunato, L. (2011). Reconstructing the History of Marriage Strategies in Indo-EuropeanSpeaking Societies: Monogamy and Polygyny. Human Biology, 83(1), 87-105. https://doi.org/10.3378/027.083.0106

Guglielmino, C. R., Viganotti, C., Hewlett, B., \& Cavalli-Sforza, L. L. (1995). Cultural variation in Africa: Role of mechanisms of transmission and adaptation. Proceedings of the National Academy of Sciences, 92(16), 7585-7589.

Harari, Y. N. (2014). Sapiens: A brief history of humankind. Random House.

Henrich, J. (2020). The Weirdest People in the World. Farrar, Straus and Giroux.

Heyer, E., Chaix, R., Pavard, S., \& Austerlitz, F. (2012). Sex-specific demographic behaviours that shape human genomic variation. Molecular Ecology, 21(3), 597-612. https://doi.org/10.1111/j.1365-294X.2011.05406.x

Jäger, G. (2018). Global-scale phylogenetic linguistic inference from lexical resources. Scientific Data, 5(1), 180189. https://doi.org/10.1038/sdata.2018.189

Jordan, F. M., \& Dunn, M. (2010). Kin term diversity is the result of multilevel, historical processes. Behavioral and Brain Sciences, 33(5), 388-388. https://doi.org/10.1017/S0140525X10001962

Knapp, R. (2011). Invisible Romans. Harvard University Press.

Murphy, R. F., \& Kasdan, L. (1959). The Structure of Parallel Cousin Marriage. American Anthropologist, 61(1), 17-29.

Passmore, S., \& Jordan, F. M. (2020). No universals in the cultural evolution of kinship terminology. Evolutionary Human Sciences, 2. https://doi.org/10.1017/ehs.2020.41

Pearl, J., \& Mackenzie, D. (2018). The book of why: the new science of cause and effect. Basic books.

Rasteiro, R., \& Chikhi, L. (2013). Female and Male Perspectives on the Neolithic Transition in Europe: Clues from Ancient and Modern Genetic Data. PLOS ONE, 8(4), e60944. https://doi.org/10.1371/journal.pone.0060944

Roberts, S., \& Winters, J. (2013). Linguistic Diversity and Traffic Accidents: Lessons from Statistical Studies of Cultural Traits. PLOS ONE, 8(8), e70902. https://doi.org/10.1371/journal.pone.0070902 
Scheidel, W. (2009). A peculiar institution? Greco-Roman monogamy in global context. The History of the Family, 14(3), 280-291. https://doi.org/10.1016/j.hisfam.2009.06.001

Schulz, J., Bahrami-Rad, D., Beauchamp, J., \& Henrich, J. (2018). The Origins of WEIRD Psychology (SSRN Scholarly Paper No. ID 3201031). Rochester, NY: Social Science Research Network. Retrieved from Social Science Research Network website: https://papers.ssrn.com/abstract $=3201031$

Schulz, J. F., Bahrami-Rad, D., Beauchamp, J. P., \& Henrich, J. (2019). The Church, intensive kinship, and global psychological variation. Science, 366(6466), eaau5141. https://doi.org/10.1126/science.aau5141

Shaw, B. D., \& Saller, R. P. (1984). Close-Kin Marriage in Roman Society? Man, 19(3), 432. https://doi.org/10.2307/2802181

Shenk, M. K., Towner, M. C., Voss, E. A., \& Alam, N. (2016). Consanguineous Marriage, Kinship Ecology, and Market Transition. Current Anthropology, 57(S13), S167S180. https://doi.org/10.1086/685712

Shepher, J. (1971). Mate selection among second generation kibbutz adolescents and adults: Incest avoidance and negative imprinting. Archives of Sexual Behavior, 1(4), 293307. https://doi.org/10.1007/BF01638058

Smaldino, P. E. (2014). The cultural evolution of emergent group-level traits. Behavioral and Brain Sciences, 37(3), 243-254. https://doi.org/10.1017/S0140525X13001544 